\title{
Sex and age differences and outcomes in acute coronary syndromes
}

\author{
Zorana Vasiljevic- Pokrajcic a,*, Natasa Mickovski ${ }^{\mathrm{b}}$, Goran Davidovic ${ }^{\mathrm{c}}$, Milika Asanin ${ }^{\mathrm{a}}$, Branislav Stefanovic ${ }^{\mathrm{a}}$, \\ Gordana Krljanac ${ }^{a}$, Mina Radosavljevic- Radovanovic ${ }^{a}$, Nebojsa Radovanovic ${ }^{\text {a }}$, Ratko Lasica ${ }^{\text {a }}$, \\ Sladjan Milanović ${ }^{\mathrm{d}}$, Jovana Bjekić ${ }^{\mathrm{d}}$, Marta Majstorovic- Stakic ${ }^{\mathrm{e}}$, Danijela Trifunovic ${ }^{\mathrm{a}}$, Ana Karadzic ${ }^{\mathrm{a}}$, \\ Dubravka Rajic ${ }^{\mathrm{a}}$, Aleksandra Milosevic ${ }^{\mathrm{a}}$, Marija Zdravkovic ${ }^{\mathrm{f}}$, Jelena Saric ${ }^{\mathrm{g}}$, Raffaele Bugiardini ${ }^{\mathrm{h}}$ \\ a Clinical Center of Serbia, University of Belgrade, Medical Faculty, Belgrade, Serbia

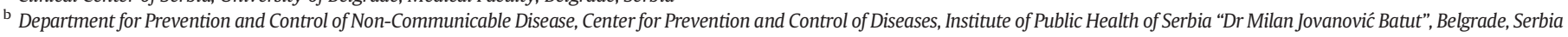 \\ c Clinical Centre Kragujevac, University Clinic, Medical Faculty Kragujevac, Serbia \\ d University of Belgrade, Institute for Medical Research, Department of Neurophysiology, Belgrade, Serbia \\ e General Hospital "Dr Dragiša Mišović", Čačak, Serbia \\ ${ }^{\mathrm{f}}$ Clinical Centre, "Bezanijska Kosa”, University of Belgrade, Medical Faculty, Belgrade, Serbia \\ g Clinical Centre, "BezanijskaKosa”, Belgrade, Serbia \\ h Department of Experimental, Diagnostics and Specialty Medicine, University of Bologna, Italy
}

\section{A R T I C L E I N F O}

\section{Article history:}

Received 30 May 2016

Accepted 25 June 2016

Available online 27 June 2016

\section{Keywords:}

Acute coronary syndrome

Sex differences

Age differences

Outcomes

\begin{abstract}
A B S T R A C T
Background: There is conflicting information about sex differences in presentation, treatment, and outcome after acute coronary syndromes (ACS) in the era of reperfusion therapy and percutaneous coronary intervention. The aim of this study was to examine presentation, acute therapy, and outcomes of men and women with ACS with special emphasis on their relationship with younger age ( $\leq 65$ years).

Methods: From January 2010 to June 2015, we enrolled 5140 patients from 3 primary PCI capable hospitals. Patients were registered according to the International Survey of Acute Coronary Syndrome in Transitional Countries (ISACS-TC) registry protocol (ClinicalTrials.gov: NCT01218776). The primary outcome was the incidence of in-hospital mortality.

Results: The study population was constituted by 2876 patients younger than 65 years and 2294 patients older. Women were older than men in both the young $(56.2 \pm 6.6$ vs. $54.1 \pm 7.4)$ and old $(74.9 \pm 6.4$ vs. $73.6 \pm$ 6.0) age groups. There were 3421 (66.2\%) patients with ST elevation ACS (STE-ACS) and 1719 (33.8\%) patients without ST elevation ACS (NSTE-ACS). In STE-ACS, the percentage of patients who failed to receive reperfusion was higher in women than in men either in the young (21.7\% vs. $15.8 \%$ ) than in the elderly (35.2\% vs. $29.6 \%)$. There was a significant higher mortality in women in the younger age group (age-adjusted OR 1.52, 95\% CI: 1.01-2.29), but there was no sex difference in the older group (age-adjusted OR 1.10, 95\% CI: 0.87-1.41). Significantly sex differences in mortality were not seen in NSTE-ACS patients.

Conclusions: In-hospital mortality from ACS is not different between older men and women. A higher short-term mortality can be seen only in women with STEMI and age of 65 or less.
\end{abstract}

(c) 2016 Published by Elsevier Ireland Ltd.

\section{Introduction}

Cardiovascular disease (CVD) is the leading cause of morbidity and mortality in the general population with a trend of increased prevalence in older patients and men [1-4]. Prevalence of CVD among women increases with age, but CVD is still the highest cause of death in the younger women $[5,6]$. In Serbia mortality from CVD in women is one of the

* Corresponding author at: Medical Faculty, University of Belgrade, 11000 Belgrade, Serbia.

E-mail address: zoranav@eunet.rs (Z. Vasiljevic- Pokrajcic). highest in the European countries [7-9]. Many studies have shown that women with acute coronary syndromes (ACS) are less likely to undergo cardiac catheterization, as well as to receive timely reperfusion therapy $[10,11]$.

The purpose of this study was to examine presentation, acute therapy, and short-term mortality of men and women with confirmed ACS admitted from January 2010 to June 2015 in three PCI capable university centers in Belgrade and Kragujevac. In these cities, social, education and income differences between women and men are less pronounced than in other smaller cities or large cities but without PCI capable hospitals special respect to the interaction of age and gender. 


\section{Methods}

2.1. Study population

The details of the ISACS-TC registry protocol (ClinicalTrials.gov: NCT01218776) have been previously published [12-16]. Briefly, the ISACS-TC registry is a prospective, multicenter study devoted to developing and evaluating survey measures that elicit improved outcomes in most transition countries embarked on reforming health systems.

Data from 3 university PCI capable hospitals in Belgrade and Kragujevac were collected from January 2010 to June 2015 . We included in the analysis only patients who had complete data on in-hospital outcomes.

\subsection{Data collection}

Diagnosis of myocardial infarction was adjudicated according to the international standardized criteria [17]. Demographic data, patient history, and procedural and outcome data were electronically recorded. Local investigators were instructed in detail by local coordinators and by means of the ISACS-TC study protocol. At the data center, all case record forms were checked for completeness and if necessary returned to the participating hospitals for correction.

\subsection{Endpoints}

The primary endpoint was to asses in-hospital mortality in older (>65) and younger $(\leq 65)$ ACS patients. We presented data on clinical presentation, comorbidity, risk factors, previous history of CVD, in hospital medications, and reperfusion therapy in ACS patients. Subgroup analyses were performed in patients with ST elevation ACS (STE-ACS) and without ST elevation ACS (NSTE-ACS).

2.4. Statistical analysis

Data are represented as percentages or expressed as means together with standard deviations for continuous variables (i.e. age). Using $\chi^{2}$ we tested the differences between sexes in younger and older age groups regarding patient characteristics, diagnosis, and hospital treatment. Additionally, the same analytic strategy was applied in testing sex differences in older and younger STE-ACS and NSTE-ACS patients. We used odds ratio (OR) and $95 \%$ coefficient intervals $(\mathrm{CI})$ to assess the association between hospital mortality rates and gender in both age groups. Finally we used a logistic regression model in order to investigate predictors of in-hospital mortality. Significance level was set to $p<.05$, and all the analyses were performed using SPSS 16.0 (SPSS Inc., Chicago, USA) and MedCalc 12.5 (MedCalc Software, Ostend, Belgium).

\section{Results}

\subsection{ACS patients' characteristics classified by age, gender and diagnosis}

There were 5140 patients admitted with ACS: 2876 were younger than $\leq 65$ years and 2294 were older than 65 years. In both groups there were more men than women, specifically: $74.1 \%$ versus $25.9 \%$ $(p<0.001)$ in younger and $54.7 \%$ versus $45.3 \%(p<0.001)$ in the older age group. In the younger age group, there were almost three times more men than women, whereas the gender distribution was closer in the older age group. Women were, on average, older in both age groups, specifically $56.2 \pm 6.6$ versus $54.1 \pm 7.4$ in the younger and $74.9 \pm 6$ versus $73.6 \pm 6.0$ in the older age group (Table 1 ).

\subsection{STE-ACS versus NSTE-ACS}

There were more STE-ACS patients, than NSTE-ACS patients (3421/ $66.2 \%$ versus $1749 / 33.8 \%$ ). STE-ACS patients were younger (mean age $62.3 \pm 12.1$ years $)$, than NSTE-ACS patients $(65.3 \pm 11.4$ years $)$

Table 1

Baseline characteristics of ACS patients sorted by age and gender.

\begin{tabular}{lll}
\hline Demographics & $\begin{array}{l}\text { Younger pts } \leq 65 \\
\mathrm{n}=2876\end{array}$ & $\begin{array}{l}\text { Older pts }>65 \\
\mathrm{n}=2294\end{array}$ \\
\hline Gender M/W & $2132 / 744(74.1 / 25.9)$ & $1254 / 1040(54.7 / 45.3)$ \\
Age & $54.6 \pm 7.3$ & $74.2 \pm 6.2$ \\
Men & $54.1 \pm 7.4$ & $73.6 \pm 6.0$ \\
Women & $56.2 \pm 6.6$ & $74.9 \pm 6.4$ \\
\hline
\end{tabular}

Data are expressed as number (percentages) or mean \pm SD.

ACS: acute coronary syndromes; M: men; W: women.
Table 2

Baseline characteristics STE-ACS patients and NSTE-ACS patients sorted by age and gender.

\begin{tabular}{lll}
\hline Variables & $\begin{array}{l}\text { Younger pts } \leq 65 \\
(\mathrm{n}=2038)\end{array}$ & $\begin{array}{l}\text { Older pts }>65 \\
(\mathrm{n}=1383)\end{array}$ \\
\hline $\begin{array}{l}\text { STE-ACS } \\
\quad \text { Gender M/W, } \mathrm{n}(\%)\end{array}$ & $1530 / 508(75.1 / 24.9)$ & $783 / 600(56.6 / 43.4)$ \\
Age & $54.3 \pm 7.4$ & $74.1 \pm 6.3$ \\
$\quad$ Men & $53.7 \pm 7.6$ & $73.5 \pm 6.1$ \\
$\quad$ Women & $56.0 \pm 6.7$ & $74.9 \pm 6.5$ \\
NSTE-ACS & & \\
Gender M/W, n (\%) & $602 / 236(71.8 / 28.2)$ & $471 / 440(51.7 / 48.3)$ \\
Age & $55.5 \pm 6.8$ & $74.3 \pm 6.1$ \\
$\quad$ Men & $55.1 \pm 7.0$ & $73.9 \pm 5.7$ \\
Women & $56.6 \pm 6.3$ & $74.9 \pm 6.4$ \\
\hline
\end{tabular}

Data are expressed as number (percentages) or mean $\pm \mathrm{SD}$, unless otherwise stated. M: men; W: women; NSTE-ACS: non-ST-segment elevation acute coronary syndromes; STE-ACS: ST-segment elevation acute coronary syndromes.

(Table 2). The majority of STE-ACS patients were men (67.6\% versus $32.4 \% \mathrm{p}<0.001)$ and younger than 65 years of age $(59.6 \%$ versus $40.4 \% \mathrm{p}<0.001)$. The NSTE-ACS patients, were relatively more balanced regarding the age groups (47.9\% in the younger versus $52.1 \%$ in the older, $\mathrm{p}<0.001)$. Yet the NSTE-ACS group was constituted predominantly by men $(61.3 \%$ versus $38.7 \%, \mathrm{p}<0.001)$ (Table 2$)$.

\subsection{Clinical characteristics in STE-ACS patients sorted by age}

Clinical characteristics in STE-ACS patients sorted by age and gender are shown in Table 3. Younger patients had a history of prior myocardial infarction, diabetes mellitus and hypertension less often, but had a history of cigarette smoking, hyperlipidemia and family history of coronary heart disease more often. Time from symptom onset to hospital admission of more than $12 \mathrm{~h}$ was more frequent among older than younger patients ( $34.7 \%$ versus $24.9 \%$, ( $\mathrm{p}<0.001$ ). Accordingly, time from symptom onset to hospital admission of less than $6 \mathrm{~h}$ was more frequent in younger (65.0\%) than in older patients $(53.2 \%)$.

Table 3

Patients with STE-ACS compared by age.

\begin{tabular}{|c|c|c|c|}
\hline Variable & $\begin{array}{l}\text { Younger pts } \leq 65 \\
\mathrm{n}=2876\end{array}$ & $\begin{array}{l}\text { Older pts }>65 \\
n=2294\end{array}$ & $\mathrm{p}$ value \\
\hline STE-ACS & 2038 (70.9) & $1383(60.3)$ & $<0.001$ \\
\hline \multicolumn{4}{|c|}{ Medical history } \\
\hline \multicolumn{4}{|c|}{$\begin{array}{l}\text { Time from symptom onset to } \\
\text { admission }\end{array}$} \\
\hline$<6 \mathrm{~h}$ & $1647(65.0)$ & $1060(53.2)$ & $<0.001$ \\
\hline $6-12 \mathrm{~h}$ & $225(10.1)$ & $243(21.2)$ & $<0.001$ \\
\hline$>12 \mathrm{~h}$ & $630(24.9)$ & $691(34.7)$ & $<0.001$ \\
\hline Typical chest pain & $2643(93.3)$ & $2013(89.3)$ & $<0.001$ \\
\hline Killip class $>1$ & $740(25.7)$ & $965(42.1)$ & $<0.001$ \\
\hline \multicolumn{4}{|l|}{ Risk factors } \\
\hline Family history of CAD & $1613(59.7)$ & $1066(52.6)$ & $<0.001$ \\
\hline Diabetes & $585(21.2)$ & 803 (36.5) & $<0.001$ \\
\hline Hypertension & $1846(65.8)$ & $1805(80.8)$ & $<0.001$ \\
\hline Current smoker & $1473(52.6)$ & $469(23.1)$ & $<0.001$ \\
\hline Hyperlipidemia & $1379(55.2)$ & $928(46.4)$ & $<0.001$ \\
\hline \multicolumn{4}{|l|}{ Cardiovascular history } \\
\hline Angina pectoris & $356(12.4)$ & $416(18.1)$ & $<0.001$ \\
\hline Prior MI & $516(17.9)$ & $491(24.4)$ & $<0.001$ \\
\hline Prior PCI & $288(10.0)$ & $167(7.3)$ & $<0.001$ \\
\hline Prior stroke & $28(1.0)$ & $75(3.3)$ & $<0.001$ \\
\hline \multicolumn{4}{|l|}{ Comorbidities } \\
\hline COPD & $131(4.8)$ & $185(8.4)$ & $<0.001$ \\
\hline Renal diseases & $94(8.6)$ & $129(13.9)$ & $<0.001$ \\
\hline
\end{tabular}

Data are expressed as number (percentages).

CAD: coronary artery disease; COPD: chronic obstructive pulmonary disease; MI: myocardial infarction; PCI: percutaneous coronary intervention. 


\subsection{Clinical characteristics in STE-ACS patients sorted by gender}

Sex differences in STE-ACS are shown in Table 4. Women had a history of prior myocardial infarction and smoking less often, but had a history of hypertension family history of coronary diseases and diabetes mellitus more often. Women reached the hospital later than men. Fewer women presented during the first $2 \mathrm{~h}$ after onset of symptoms. There were no remarkable differences between the 2 age groups.

\subsection{Treatment}

Reperfusion therapy by primary PCI (Table 5) was performed in $74.2 \%$ of women and $78.6 \%$ of men in the age group of 65 years or less. The number of interventions was markedly reduced in the age group of more than 65 years, but sex difference still persisted (60.8\% versus $67.4 \%$ ). Interestingly, there were no differences in fibrinolysis between sexes in the younger age group, but fibrinolysis was more frequently used in women in the older group of patients. Yet, there were also sex differences in the use of concomitant medical treatment with aspirin, heparins, or angiotensin-converting enzyme inhibitors being given less to women (Table 5).

\subsection{Mortality rates}

The overall in-hospital mortality rate was higher among women than men (10.3\% versus 6.9\%; OR 1.56 95\%CI 1.28-1.91 p <.001). Yet, in STE-ACS there was a significant higher mortality in women in the younger age group (age-adjusted OR 1.52, 95\% CI: 1.01-2.29), but there was no sex difference in the older group (adjusted OR 1.10, 95\% CI: 0.87-1.41). Significantly sex differences in mortality were not seen in NSTE-ACS patients.

\section{Discussion}

Whether sex disparities in care processes and death after ACS are still present in the current era of reperfusion therapy by primary $\mathrm{PCI}$ and the extent to which differences in treatment may account for any existing mortality rate gap remain a matter of debate. In addition,
Table 5

In hospital medications for patients with STE-ACS patients classified by age and gender.

\begin{tabular}{|c|c|c|c|c|c|c|}
\hline \multirow[b]{2}{*}{ Variable } & \multicolumn{3}{|c|}{ Younger pts $\leq 65$} & \multicolumn{3}{|c|}{ Older pts $>65$} \\
\hline & $\begin{array}{l}\text { Men } \\
n= \\
1530\end{array}$ & $\begin{array}{l}\text { Women } \\
\mathrm{n}= \\
508\end{array}$ & $\begin{array}{l}\mathrm{p} \\
\text { value }\end{array}$ & $\begin{array}{l}\text { Men } \\
\mathrm{n}= \\
783\end{array}$ & $\begin{array}{l}\text { Women } \\
n= \\
600\end{array}$ & $\begin{array}{l}\mathrm{p} \\
\text { value }\end{array}$ \\
\hline \multicolumn{7}{|c|}{ Reperfusion strategy } \\
\hline $\begin{array}{l}\text { Without } \\
\text { reperfusion }\end{array}$ & 15.8 & 21.7 & $<0.001$ & 29.6 & 35.2 & 0.004 \\
\hline $\mathrm{p}-\mathrm{PCI}$ & 78.6 & 74.2 & 0.013 & 67.4 & 60.8 & $<0.001$ \\
\hline Fibrinolysis & 2.6 & 1.2 & 0.111 & 1.5 & 2.7 & 0.043 \\
\hline Aspirin $^{a}$ & 97.0 & 96.0 & 0.026 & 95.9 & 92.0 & $<0.001$ \\
\hline ACE inhibitors ${ }^{\mathrm{a}}$ & 76.2 & 74.6 & 0.380 & 79.5 & 73.5 & $<0.001$ \\
\hline Beta blockers ${ }^{\mathrm{a}}$ & 82.0 & 79.1 & 0.081 & 73.1 & 69.6 & 0.064 \\
\hline Clopidogrel & 95.2 & 93.4 & 0.058 & 91.4 & 89.5 & 0.122 \\
\hline UFH & 37.0 & 32.1 & 0.016 & 38.8 & 34.4 & 0.030 \\
\hline LMWH & 55.0 & 53.0 & 0.345 & 56.1 & 50.9 & 0.013 \\
\hline Nitrates & 19.3 & 22.0 & 0.113 & 34.3 & 26.1 & $<0.001$ \\
\hline Statins ${ }^{a}$ & 95.6 & 92.6 & $<0.001$ & 87.7 & 87.5 & 0.885 \\
\hline
\end{tabular}

Data are expressed as percentages.

ACE: angiotensin converting enzyme; LMWH: low molecular weight heparins; STE-ACS: ST-segment elevation acute coronary syndromes; UFH: unfractioned heparins.

a Medications administered within $24 \mathrm{~h}$ of hospital admission.

older age and associated comorbidities have been suggested as a major explanation of such disparities, but reasons for similar disparities in younger patients have been less well studied [1,2,18,19]. We found that the in-hospital mortality from ACS is not different between men and women. A higher short-term mortality can be seen only in women with STEMI of age of 65 years or less.

\subsection{STE-ACS, reperfusion therapy and in-hospital mortality}

Consistent with most previous investigations, younger women with STEMI in our registry had a higher risk for hospital death than men [9, 10,20-23]. Less use of reperfusion therapy among older women compared with men has been consistently reported by many studies $[18,24-27]$. The reasons for younger women not to be treated according to guidelines are more impenetrable than in the elderly. Atypical symptoms may have a great effect on narrowing sex differences in

Table 4

Patients with STE-ACS compared by age and gender.

\begin{tabular}{|c|c|c|c|c|c|c|}
\hline \multirow[t]{2}{*}{ Variable } & \multicolumn{3}{|c|}{ Younger pts $\leq 65$} & \multicolumn{3}{|c|}{ Older pts $>65$} \\
\hline & $\begin{array}{l}\text { Men } \\
n=2132\end{array}$ & $\begin{array}{l}\text { Women } \\
\mathrm{n}=744\end{array}$ & $\begin{array}{l}\mathrm{p} \\
\text { value }\end{array}$ & $\begin{array}{l}\text { Men } \\
\mathrm{n}=1254\end{array}$ & $\begin{array}{l}\text { Women } \\
\mathrm{n}=1040\end{array}$ & $\begin{array}{l}\mathrm{p} \\
\text { value }\end{array}$ \\
\hline \multicolumn{7}{|l|}{ Medical history } \\
\hline Typical chest pain & 93.3 & 93.4 & 0.925 & 89.5 & 89.0 & 0.700 \\
\hline Killip Class $>1$ & 25.6 & 26.1 & 0.788 & 41.3 & 43.1 & 0.385 \\
\hline \multicolumn{7}{|c|}{ Time from symptom onset to admission } \\
\hline$<2 \mathrm{~h}$ & 33.1 & 29.3 & 0.056 & 19.5 & 16.2 & 0.041 \\
\hline $2-6 \mathrm{~h}$ & 33.0 & 32.5 & 0.803 & 34.4 & 36.1 & 0.396 \\
\hline $6-12 \mathrm{~h}$ & 9.5 & 11.6 & 0.101 & 11.6 & 12.9 & 0.343 \\
\hline $12-24 \mathrm{~h}$ & 10.7 & 11.8 & 0.409 & 14.5 & 15.1 & 0.687 \\
\hline$>24 \mathrm{~h}$ & 13.6 & 14.7 & 0.496 & 20.1 & 19.7 & 0.811 \\
\hline \multicolumn{7}{|l|}{ Risk factors } \\
\hline Hypertension & 63.0 & 73.8 & $<0.001$ & 76.9 & 85.5 & $<0.001$ \\
\hline Diabetes mellitus & 19.8 & 25.3 & 0.001 & 33.5 & 40.0 & 0.001 \\
\hline Family history of CAD & 58.7 & 62.5 & 0.001 & 48.3 & 58.0 & $<0.001$ \\
\hline Current smoker & 54.1 & 48.5 & 0.008 & 29.0 & 16.0 & $<0.001$ \\
\hline Hyperlipidemia & 54.5 & 56.9 & 0.257 & 44.4 & 48.8 & 0.035 \\
\hline \multicolumn{7}{|l|}{ Cardiovascular history } \\
\hline Angina pectoris & 11.5 & 14.8 & 0.019 & 16.7 & 19.9 & 0.048 \\
\hline Prior MI & 18.5 & 16.3 & 0.178 & 23.9 & 18.4 & 0.001 \\
\hline Prior PCI & 9.7 & 10.9 & 0.348 & 6.4 & 8.4 & 0.067 \\
\hline Prior stroke & 1.0 & 0.9 & 0.811 & 3.1 & 3.5 & 0.592 \\
\hline \multicolumn{7}{|l|}{ Comorbidities } \\
\hline COPD & 4.3 & 6.0 & 0.060 & 9.5 & 7.0 & 0.031 \\
\hline Renal diseases & 2.7 & 3.5 & 0.236 & 12.3 & 9.9 & 0.069 \\
\hline
\end{tabular}

Data are expressed as percentages.

CAD: coronary artery disease; COPD: chronic obstructive pulmonary disease; MI: myocardial infarction; PCI: percutaneous coronary intervention. 
administration of evidence based therapies among patients [28]. Atypical symptoms are associated with patient delay in seeking medical attention resulting in late diagnosis by both the emergency department and local physicians $[29,30]$. In the Serbian data, atypical symptoms were more frequent in the elderly, but there were no differences in their presentation among women and men. Thus presentation with atypical symptoms cannot be a factor for inequality in treatment. Nevertheless women in Serbia more often had a longer pre-hospital delay than men, which suggest a high degree of awareness of the disease. Patients themselves and the public healthcare sector need to be more educated about the high risk of death experienced by women with STE-ACS. More education may help to encourage earlier contact with healthcare service.

\subsection{STE-ACS, risk factors and in-hospital mortality}

Diabetes was also considered among the explanatory variables, given the findings of a worse outcome in women with diabetes compared with men with STE-ACS [21]. In both age groups, diabetes was more prevalent in women. Diabetes was associated with less use of reperfusion therapy but there was no interaction with sex implying similar treatment in men and women.

The same considerations can be done for hypertension. In both age groups, hypertension was more prevalent in women [20,21]. However, even after controlling for traditional risk factors, sex disparities persisted.

\subsection{STE-ACS and in-hospital mortality: unmeasured factors}

The greater short term mortality for younger women suggests contribution from unmeasured confounders. Such factors could include vasospastic disease, or microcirculatory disease, which may often occur in women with nonobstructive coronary disease and may result in waxing and waning of symptoms and partial resolution of ST-elevation [31-34]. All of these factors may, therefore confounding and may refrain physicians from reperfusion therapy. The fact that most of the women with vasospastic disease exhibit a disorder of the entire coronary arterial tree is certainly in keeping with this hypothesis. Vasospastic disease may result in inappropriate coronary constriction during increased sympathetic drive [35] which, in turn, may lead to plaque disruption or erosion. Vasospastic disease may also induce "transmural coronary steal", which describes the phenomenon that can occur when vasodilation in the subepicardial layers lowers the perfusion pressure to the subendocardial layers, a vascular bed in which flow is pressure-dependent [36-38].

\subsection{Study limitations}

Because we used data from 3 tertiary centers in Serbia, our data may not be representative of the country. Furthermore, the treatment decisions were not randomized and were left to the discretion of the treating physician.

\section{Conclusions}

Our findings extend the previous literature, primarily based on US patients [39], by showing significant gender differences in outcomes by age in Serbia, a middle-income country with a large, potentially very different patient population and with different challenges in healthcare services. As we have shown, commonly cited clinical factors do not entirely explain why reperfusion is being withheld, especially among younger women. There is a strict relationship between lack of reperfusion therapy and short term mortality.

\section{Conflict of interest}

The authors report no relationships that could be construed as a conflict of interest $[40,41]$.

\section{Acknowledgments}

Zorana Vasiljevic-Pokrajcic was supported by a project grant (\#ON175084) from the Ministry for Education, Science and Technological Development of Republic of Serbia.

Sladjan D. Milanović was supported by a project grant (\#ON175096) from the Ministry for Education, Science and Technological Development of Republic of Serbia.

Jovana Bjekić was supported by a project grant (\#ON175012) from the Ministry for Education, Science and Technological Development of Republic of Serbia.

\section{References}

[1] V. Vaccarino, L. Badimon, R. Corti, et al., Working group on Coronary Pathophysiology and Microcirculation. Ischemic heart disease in female: are there sex differences in pathophysiology and risk factors? Position paper from the working group on coronary pathophysiology and microcirculation of the European Society of Cardiology, Cardiovasc. Res. 90 (2011) 9-17.

[2] V. Vaccarino, L. Badimon, R. Corti, et al., Presentation, management, and outcomes of ischaemic heart disease in women, Nat. Rev. Cardiol. 10 (2013) 508-518.

[3] L. Gholizadeh, P. Davidson, More similarities than differences: an international comparison of CVD mortality and risk factors in female, Health Care Female Int. 29 (2008) 3-22.

[4] J.A. Finegold, P. Asaria, D.P. Francis, Mortality from ischaemic heart disease by country, region, and age: statistics from World Health Organisation and United Nations, Int. J. Cardiol. 168 (2013) 934-945.

[5] T.M. Wizemann, M. Pardue (Eds.), National Research Council, Institute of Medicine Committee on Understanding the Biology of Sex and Gender Differences. Exploring the biological contributions to human health: does sex matter? The National Academies Press, Washington, DC, 2001.

[6] D. Mozaffarian, E.J. Benjamin, A.S. Go, et al., Heart disease and stroke statistics-2015 update: a report from the American Heart Association, Circulation 131 (2015) e29-e322.

[7] Instiute of Public Health of Serbia, "Dr Milan JovanovicBatut", Health Statistical Yearbook of Republic of Serbia 2014, http://www.batut.org.rs 2015 (accessed 14.04.2016).

[8] Z. Vasiljevic, N. Mickovski-Katalina, G. Krljanac, et al., Coronary care unit and primary percutaneous coronary intervention networks improve the standard of care: reperfusion therapy in ST elevation myocardial infarction in Serbia from 2002 to 2008, J. Cardiovasc. Med. 12 (2011) 300-302.

[9] Z. Vasiljevic, G. Krljanac, G. Davidovic, et al., Gender differences in case fatality rates of acute myocardial infarction in Serbia, Eur. Heart J. Suppl. 16 (Suppl A) (2014) A48-A55.

[10] H. Jneid, G.C. Fonarow, C.P. Cannon, et al., Sex differences in medical care and early death after acute myocardial infarction, Circulation 118 (2008) 2803-2810.

[11] I. Wijnbergen, J. Tijssen, M. van 't Veer, R. Michels, N.H. Pijls, Gender differences in long-term outcome after primary percutaneous intervention for ST-segment elevation myocardial infarction, Catheter. Cardiovasc. Interv. 82 (2013) 379-384.

[12] R. Bugiardini, L. Badimon, O. Manfrini, on the behalf of the ISACS-TC Investigators, Rationale and design of the ISACS-TC (International Survey of Acute Coronary Syndromes in Transitional Countries) project, Eur. Heart J. Suppl. 16 (suppl. A) (2014) A1-A6.

[13] R. Bugiardini, M. Dorobantu, Z. Vasiljevic, et al., Unfractionated heparin-clopidogrel interaction in ST-elevation myocardial infarction not receiving reperfusion therapy, Atherosclerosis 241 (2015) 151-156.

[14] R. Bugiardini, O. Manfrini, M.M. Stakic, et al., Exploring in-hospital death from myocardial infarction in Eastern Europe: from the International Registry of Acute Coronary Syndromes in Transitional Countries (ISACS-TC); on the Behalf of the Working Group on Coronary Pathophysiology \& Microcirculation of the European Society of Cardiology, Curr. Vasc. Pharmacol. 12 (2014) 903-909.

[15] R. Bugiardini, E. Cenko, B. Ricci, et al., Comparison of early versus delayed oral $\beta$ blockers in acute coronary syndromes and effect on outcomes, Am. J. Cardiol. 117 (2016) 760-767.

[16] E. Cenko, B. Ricci, S. Kedev, et al., Reperfusion therapy for ST-elevation acute myocardial infarction in Eastern Europe: the ISACS-TC registry, Eur. Heart J. Qual. Care Clin. Outcomes 2 (2016) 45-51.

[17] K. Thygesen, J.S. Alpert, A.S. Jaffe, M.L. Simoons, B.R. Chaitman, H.D. White, Third universal definition of myocardial infarction, Nat. Rev. Cardiol. 9 (2012) 620-633.

[18] D. Radovanovic, P. Erne, P. Urban, O. Bertel, H. Rickli, J.M. Gaspoz, Gender differences in management and outcomes in patients with acute coronary syndromes: results on 20290 patients from the AMIS Plus Registry, Heart 93 (2007) 1369-1375.

[19] A. Gupta, Y. Wang, J.A. Spertus, et al., Trends in acute myocardial infarction in young patients and differences by sex and race, 2001 to 2010, J. Am. Coll. Cardiol. 64 (2014) 337-345. 
[20] V. Vaccarino, L. Parsons, N.R. Every, H.V. Barron, H.M. Krumholz, Sex based differences in early mortality after myocardial infarction: National Registry of Myocardial Infarction 2 Participants, N. Engl. J. Med. 341 (1999) 217-225.

[21] S. Yusuf, S. Hawken, S. Ounpuu, et al., Effect of potentially modifiable risk factors associated with myocardial infarction in 52 countries (the INTERHEART study): casecontrol study, Lancet 364 (2004) 937-952.

[22] G. Tatu-Chitoiu, M. Cinteza, M. Dorobantu, et al., In-hospital case fatality rates for acute myocardial infarction in Romania, CMAJ 180 (2009) 1207-1213.

[23] R. Bugiardini, J.L. Estrada, K. Nikus, A.S. Hall, O. Manfrini, Gender bias in acute coronary syndromes, Curr. Vasc. Pharmacol. 8 (2010) 276-284

[24] R.R. Kalyani, M. Lazo, P. Ouyang, et al., Sex differences in diabetes and risk of incident coronary artery disease in healthy young and middle-aged adults, Diabetes Care 37 (2014) 830-838.

[25] L. Mosca, E.J. Benjamin, K. Berra, et al., Effectiveness-based guidelines for the prevention of cardiovascular disease in female-2011 update: a guideline from the American Heart Association, Circulation 123 (2011) 1243-1262.

[26] M.G. Van der Meer, H.M. Nathoe, Y. van der Graaf, P.A. Doevendans, Y. Appelman, Worse outcome in women with STEMI: a systematic review of prognostic studies, Eur. J. Clin. Investig. 45 (2015) 226-235.

[27] 1. Cohen, C. Boiangiu, M. Abidi, Therapy for ST-segment elevation myocardial infarction patients who present late or are ineligible for reperfusion therapy, J. Am. Coll. Cardiol. 55 (2010) 1895-1906.

[28] R. Bugiardini, Women, 'non-specific' chest pain, and normal or near-normal coronary angiograms are not synonymous with favourable outcome, Eur. Heart J. 27 (2006) 1387-1389.

[29] H. Benamer, M. Tafflet, S. Bataille, et al., Female gender is an independent predictor of in-hospital mortality after STEMI in the era of primary PCI: insight from the greater Paris area PCI Registry, EuroIntervention 9 (2011) 1073-1079.

[30] G. D'Onofrio, B. Safdar, J.H. Lichtman, et al., Sex differences in reperfusion in young patients with ST-segment-elevation myocardial infarction: results from the VIRGO study, Circulation 131 (2015) 1324-1332.
[31] O. Manfrini, R. Bugiardini, Barriers to clinical risk scores adoption, Eur. Heart J. 28 (2007) 1045-1046.

[32] R. Bugiardini, A. Pozzati, F. Ottani, G.L. Morgagni, P. Puddu, Vasotonic angina: a spectrum of ischemic syndromes involving functional abnormalities of the epicardial and microvascular coronary circulation, J. Am. Coll. Cardiol. 22 (1993) 417-425.

[33] E. Cenko, R. Bugiardini, Vasotonic angina as a cause of myocardial ischemia in women, Cardiovasc. Drugs Ther. 29 (2015) 339-345.

[34] C. Pizzi, R. Bugiardini, Further insights into syndrome X, Heart 96 (2010) 1865-1867.

[35] O. Manfrini, C. Pizzi, M. Viecca, R. Bugiardini, Abnormalities of cardiac autonomic nervous activity correlate with expansive coronary artery remodeling, Atherosclerosis 197 (2008) 183-189.

[36] R. Bugiardini, M. Galvani, D. Ferrini, et al., Myocardial ischemia induced by prostacyclin and iloprost, Clin. Pharmacol. Ther. 38 (1985) 101-108.

[37] R. Bugiardini, M. Galvani, D. Ferrini, et al., Myocardial ischemia during intravenous prostacyclin administration: hemodynamic findings and precautionary measures, Am. Heart J. 113 (2 Pt 1) (1987) 234-240.

[38] W.M. Chilian, P.H. Ackell, Transmural differences in sympathetic coronary constriction during exercise in the presence of coronary stenosis, Circ. Res. 62 (1988) $216-225$.

[39] Z. Zhang, J. Fang, C. Gillespie, G. Wang, Y. Hong, P.W. Yoon, Age specific gender differences in in-hospital mortality by type of acute myocardial infarction, Am. J. Cardiol. 103 (2012) 1097-1103.

[40] L.G. Shewan, G.M.C. Rosano, M.Y. Henein, A.J.S. Coats, A statement on ethical standards in publishing scientific articles in the International Journal of Cardiology family of journals, Int. J. Cardiol. 170 (2014) 253-254.

[41] F. Alfonso, A. Timmis, F.J. Pinto, et al., Conflict of interest policies and disclosure requirements among European Society of Cardiology National Cardiovascular Journals, Eur. Heart J. 33 (2012) 587-594. 